DOI: https://doi.org/10.30749/2177-8337.v24n49p136-156

\title{
A DIFICULDADE DO ACESSO À SAÚDE PELO GRUPO LGBTI NO BRASIL DURANTE A PANDEMIA: UMA ANÁLISE À LUZ DA TEORIA DA EFICÁCIA HORIZONTAL DOS DIREITOS HUMANOS
}

\section{THE DIFFICULTY OF ACCESS TO HEALTH BY THE LGBTI GROUP IN BRAZIL DURING THE PANDEMIC: AN ANALYSIS IN THE LIGHT OF THE THEORY OF HORIZONTAL EFFECTIVENESS OF HUMAN RIGHTS}

Beatriz Pristilo Ghetti* Daniela Hruschka Bahdur**

\begin{abstract}
Resumo: $O$ presente estudo tem como objetivo discorrer sobre a dificuldade enfrentada pela população LGBTI no Brasil no que tange ao acesso à saúde. Trata-se aqui de um direito social já de segunda dimensão dos Direitos Humanos, incorporado pela Constituição brasileira. Contudo, observa-se uma marginalização maior desse grupo, visto que a pandemia da Covid-19 acarretou prejuízos à saúde mental e maior dificuldade de acesso aos locais de atendimento. Dessa forma, o estudo busca a compreensão das violações cometidas a esse grupo no país, resultantes de um longo processo de discriminação; além de apontar um possível passo na resolução do problema com base na teoria da eficácia horizontal dos Direitos Humanos.
\end{abstract}

Palavras-chave: Pandemia. Saúde. LGBTI. Eficácia Horizontal. Direitos Humanos.

Abstract: The current study aims to discuss about the difficulty faced by the LGBTI population in Brazil with regard to access to health. It is known to be a social right framed in the second dimension of Human Rights, incorporated by the Brazilian Constitution. However, it is seen a bigger marginalization of this group, due to the fact that the Covid-19 pandemic causes damage to mental health and to access to places of care. The expected results of the study are to understand the scope of the violations committed against this group in the country, caused by a long process of discrimination; and to point out a possible step in solving the problem based on the theory of the horizontal effectiveness of Human Rights.

Key-words: Pandemic. Health. LGBTI. Horizontal Effectiveness. Human Rights.

Recebido em: 01/10/2020. Aceito em: 07/10/2020.

\footnotetext{
* Graduanda em Direito pela Universidade Estadual de Londrina (UEL) Londrina, PR, BR. E-mail: beatrizghetti@gmail.com.

** Mestre em Direito Econômico Europeu e Internacional pela LMU Universidade de Munique Alemanha. Especialista em Direito Tributário e Bacharel em Direito pela Universidade Estadual de Londrina (UEL) Londrina, PR, BR. E-mail: danielahru.adv@gmail.com.
} 


\section{INTRODUÇÃO}

O direito à saúde é direito de segunda dimensão, quando classificado dentro da teoria dos Direitos Humanos dentro dos chamados Direitos Sociais. Conforme Sarlet (2012, p. 47): "Caracterizam-se por outorgarem ao indivíduo direitos à prestações sociais estatais, [...] revelando uma transição das liberdades formais abstratas para as liberdades materiais concretas". Nessa diretriz, a Constituição brasileira absorveu o sistema de proteção internacional dos Direitos Humanos, incluindo a saúde em seu extenso rol de Direitos Fundamentais (nomenclatura utilizada para denotar as normas positivadas na ordem jurídica interna).

Entretanto, na prática, percebe-se que o acesso à saúde é dificultado para muitos, por vezes, devido à discriminação. Faz-se necessário falar especificamente da população LGBTI 1 , pois pesquisas mostram que o preconceito contra homoafetivos e a falta de informação sobre questões de gênero estão por trás do atendimento de má qualidade (NAÇÕES UNIDAS BRASIL, 2016). Segundo a Organização Pan-americana da Saúde (OPAS), nos centros de atendimento, esse grupo fica sujeito à abusos e até à recusa da prestação de cuidados.

Além disso, a atuação estatal peca na proteção desse grupo a partir do momento em que há uma omissão legislativa tanto no quesito de criminalização da homofobia, quanto de políticas públicas inclusivas. Recentemente, o plenário do Supremo Tribunal Federal (STF) decidiu pela aplicação da lei do racismo em atos homofóbicos e transfóbicos, até que o Congresso Nacional edite lei específica.

Tal questão tem uma piora significativa na atualidade, uma vez que a pandemia da Covid-19 expõe ainda mais a população LGBTI à marginalização. $O$ Ministério da Mulher, Família e dos Direitos Humanos (MMFDH) lançou, no início de abril, uma cartilha com informações sobre a prevenção contra o coronavírus direcionada às pessoas LGBTI. O documento possuía recomendações para profissionais do sexo e usuários de drogas.

Se, por um lado, é importante pensar na situação dos dependentes químicos e envolvidos em prostituição, por outro, é um erro associar isso exclusivamente à população LGBTI, o que levou a uma série de críticas por parte da sociedade civil.

1 Lésbicas, Gays, Bissexuais, Travestis, Transexuais, Transgêneros e Intersexuais. 
Assim, a cartilha foi modificada e revisada pela Diretoria de Promoção dos Direitos LGBT, mas ainda assim não foi suficiente para tratar da situação atual enfrentada pelo grupo.

Em meio à crise nos bancos de sangue, com queda de doações desde 0 início da pandemia, o Ministério da Saúde manteve as restrições aos homoafetivos. A esses, foi vedado o direito de doar sangue sob o pretexto de maior incidência de doenças sexualmente transmissíveis. Contudo, o que deveria ser analisado é se a pessoa possui comportamento de risco, não importando sua orientação sexual. Nessa linha de pensamento, o STF julgou uma ação direta de inconstitucionalidade, decidindo, por maioria, pelo fim das restrições aos homossexuais (OLIVEIRA, 2020).

Corroborando para esse cenário de marginalização, temos o aumento de desemprego durante a pandemia do coronavírus. Segundo Guilherme Thomazi (RDC TV, 2020), especialista em saúde pública, já é difícil para a população LGBTI ingressar no mercado de trabalho formal e, em uma situação de calamidade, essas são as primeiras pessoas a serem demitidas. Isso, em adição a recomendação de isolamento social, trouxe uma piora significativa na saúde mental dos gays, lésbicas, bissexuais, travestis, transexuais, transgêneros e intersexuais. Mesmo assim, não se observa uma mobilização do Estado para sanar tais prejuízos, valendo recordar que a saúde mental também é um Direito Humano tutelado pelo direito pátrio e pela ordem internacional.

Ainda, conforme pesquisas, a violência psicológica e física contra a população LGBTI aumentou durante a pandemia. Sabe-se que dentro do ambiente familiar, muitas dessas pessoas não são aceitas, o que resulta em diversas formas de agressão verbal. Em relação a violência física, os dados indicam que, no primeiro semestre de 2020, o aumento no número de assassinatos contra a população transexual foi na ordem de 49\%. (ASSOCIAÇÃO NACIONAL DE TRAVESTIS E TRANSEXUAIS, 2020).

À vista da problemática, percebe-se que, apesar de necessária a atuação estatal, são insuficientes as políticas públicas especificas à este grupo vulnerável, sendo necessária, inclusive, a atuação de particulares em situação favorecida a auxiliarem em tal propósito, ou seja, a atuação da sociedade civil. 
O que antes era defendido apenas como um direito prestacional do Estado, agora é estendido para toda uma sociedade em busca da igualdade e equidade social, para aproximar ainda mais as classes sociais por meio do espírito solidário do bem-estar geral (OTERO; RODRIGUES, 2014, p. 109).

Dessa forma, o presente estudo busca entender como a sociedade civil pode auxiliar no acesso efetivo e não discriminatório do grupo LGBTI à saúde durante a pandemia do corona vírus. Para tal, será feita uma análise com base na teoria da eficácia horizontal dos Direitos Humanos, a qual dispõe que as pessoas não podem, em suas relações privadas, agirem de maneira nociva à dignidade humana (BARRETTO, 2017). A pesquisa realizada é de natureza qualitativa e seguirá a metodologia bibliográfica, de natureza descritiva.

\section{A SAÚDE COMO DIREITO HUMANO E SUA IMPLEMENTAÇÃO NO BRASIL}

Segundo Barretto (2017), os Direitos Humanos são um conjunto de direitos que concretizam a dignidade da pessoa humana. O Estado é responsável por promovê-los, ao mesmo tempo em que é limitado por eles, uma vez que não Ihe é permitido cometer arbitrariedades. Conforme Mazzuoli (2019), a nomenclatura designa os direitos positivados em tratados e costumes internacionais, tutelados pelo Direito Internacional Público, enquanto a expressão 'direitos fundamentais' abrange aqueles positivados no Direito interno.

Como dito anteriormente, o direito à saúde é um dos Direitos Humanos de segunda dimensão, os quais estão vinculados ao princípio da igualdade. Tais direitos possuem caráter "positivo", pois angariam papel ativo do Estado na realização da justiça social (SARLET, 2012). Nesse sentido:

O Estado pode atuar diretamente em favor desses direitos, mas pode, também, ensejar a participação de outras instituições e mesmo de pessoas da coletividade, que deverão atuar com o propósito de concretizá-los (FACHIN, 2019, p. 221).

Para compreender melhor a segunda dimensão dos Direitos Humanos, faz-se necessário mencionar documentos como: a Declaração de Direitos do Povo Trabalhador e Explorado - publicada em 1918, que materializou a Revolução Russa e propagou o princípio da igualdade - e a Declaração Universal dos Direitos Humanos proclamada pela Organização das Nações Unidas (ONU) em 1948, que estabeleceu 
pela primeira vez definições e o compromisso de proteção universal dos direitos humanos, além de conciliar os valores da liberdade e da igualdade.

Foi após a Segunda Guerra Mundial, que os direitos de igualdade acabaram sendo consagrados nas Constituições e pactos internacionais. Destaca-se, nesse período, a contribuição da Proclamação de Teerã - promulgada pela ONU em 1968, como resultado da I Conferência Mundial de Direitos Humanos- ao promover a indivisibilidade dos direitos, preconizou em seu artigo 13, a impossibilidade de realizar-se os direitos civis e políticos sem a promoção dos direitos econômicos, sociais e culturais.

Para falar especificamente do direito à saúde, destaca-se o Pacto Internacional de Direitos Econômicos, Sociais e Culturais, adotado pela Assembleia Geral das Nações Unidas em 1966. Seu artigo 12 preconiza:

1. Os Estados Partes do presente Pacto reconhecem o direito de toda pessoa de desfrutar o mais elevado nível possível de saúde física e mental.

2. As medidas que os Estados Partes do presente Pacto deverão adotar com o fim de assegurar o pleno exercício desse direito incluirão as medidas que se façam necessárias para assegurar: [...]

d) A criação de condições que assegurem a todos, assistência médica e serviços médicos em caso de enfermidade. (BRASIL, 1992).

É preciso demonstrar o status que os Direitos Humanos possuem em nosso ordenamento jurídico. Com base nos estudos de Mazzuoli (2011), pode-se dizer que os tratados internacionais de Direitos Humanos ratificados pelo Brasil possuem status constitucional. Tal afirmativa tem respaldo no artigo $5^{\circ} \S 3^{\circ}$ do texto constitucional, o qual confere equivalência às emendas constitucionais aos tratados e convenções internacionais aprovados, em cada Casa do Congresso Nacional, em dois turnos, por três quintos dos membros.

O Pacto Internacional de Direitos Econômicos, Sociais e Culturais foi assinado e ratificado pelo Brasil em 1992, entretanto, nossa Constituição Federal já abordava a saúde em seu extenso rol de Direitos Fundamentais. O artigo 196 da Carta garante que a saúde é direito de todos e dever do Estado, o qual deve promover acesso universal e igualitário às pessoas (BRASIL, 1988). Segundo estudos de Aith (2007), a constitucionalização do direito à saúde no Brasil foi consequência da mobilização de grupos em busca do reconhecimento dos direitos sociais, como forma de diminuir as desigualdades e reestabelecer a democracia, após um longo período de ditadura 
militar. Percebe-se, então, que a sociedade tem papel crucial na inovação do ordenamento jurídico. As relações sociais, com seu dinamismo, fundamentam os valores a serem tutelados pelo Direito em cada momento social (MARTINS; MALUF, 2016).

Observa-se, contudo, uma incoerência entre a norma jurídica que institui o direito à saúde e a sua efetiva aplicação, já que ele depende da alocação de recursos financeiros, técnicos, e políticos, envolvendo interesses para viabilizar os direitos sociais no plano organizacional (NOGUEIRA, 2002 apud D'ÁVILA; SALIBA, 2017). O acesso igualitário à saúde foi tentado através da criação do Sistema Único de Saúde (SUS), no entanto, alguns pontos da sociedade brasileira interferem no objetivo ensejado, tais como: os conflitos sociais, a não implementação de políticas públicas inclusivas, entre outros. De acordo com D'Ávila e Saliba (2017), isso demonstra a ligação do acesso à saúde com a busca pela justiça social.

Uma curiosidade é que nossa Constituição, no artigo $5^{\circ} \S 1^{\circ}$, positivou a aplicação imediata de todos os Direitos Fundamentais, enquanto a ordem internacional costuma reconhecer tal aplicação apenas aos direitos individuais, deixando aos sociais caráter programático (BARRETTO, 2017) servindo como base para decisões do Supremo Tribunal Federal, nas quais a Corte tem determinado ao Poder Público que adote medidas concretas para a efetivação do direito à saúde.

\section{A DIFICULDADE DO ACESSO À SAÚDE PELA POPULAÇÃO LGBTI}

Ao observar o texto da Constituição da Organização Mundial de Saúde, temse que:

\footnotetext{
Os Estados-partes desta Constituição declaram, em conformidade com a Carta das Nações Unidas, que os seguintes princípios são básicos para a felicidade, relações harmoniosas e segurança de todos os povos:

Saúde é um estado de completo bem-estar físico, mental e social e não apenas a ausência de doença ou enfermidade.

O gozo do mais alto padrão de saúde possível é um dos direitos fundamentais de todo ser humano, sem distinção de raça, religião, crença política, condição econômica ou social.

A saúde de todos os povos é fundamental para a obtenção da paz e segurança e depende da mais plena cooperação de indivíduos e Estados. [...]

A extensão a todos os povos dos benefícios dos conhecimentos médicos, psicológicos e afins é essencial para a plena obtenção da saúde.
} 
A opinião informada e a cooperação ativa por parte do público são de extrema importância para a melhoria da saúde das pessoas.

Os governos têm uma responsabilidade pela saúde de seus povos, que só pode ser cumprida com a provisão de medidas sociais e de saúde adequadas. (WORLD HEALTH ORGANIZATION, 2020, p. 7, tradução nossa).

Percebe-se que o documento constitutivo da OMS procurou enfatizar o papel do Estado e dos indivíduos na promoção da saúde; o acesso igualitário às pessoas; e a ideia de que a saúde traspassa a ausência de doença, tratando-se de um estado de bem-estar geral. Essa última afirmação é especialmente significativa para tratar do acesso à saúde no Brasil, pois, apesar de possuirmos um sistema de saúde público e gratuito, muitas pessoas não têm acesso ao sistema para a manutenção do "[...] completo de bem-estar físico, mental e social [...]" descrito.

A saúde está ligada ao desenvolvimento social de maneira geral, e, com isso, grupos minoritários são constantemente privados de condições essenciais à sua própria existência. No caso da população LGBTI, verifica-se um estigma na sociedade como um todo, que se estende ao setor da Saúde. Para a Organização Mundial da Saúde e a Organização Pan-Americana da Saúde: "[...] a discriminação pode resultar na recusa absoluta da prestação de cuidados, atenção de má qualidade e tratamento desrespeitoso ou abusivo, entre outros [...]" (ORGANIZAÇÃO PAN-AMERICANA DA SAÚDE BRASIL, 2016).

Em busca de catalogar e propor soluções a tal situação, foram elaborados, em 2006, os Princípios de Yogyakarta, um documento sobre Direitos humanos no âmbito da orientação sexual e da identidade de gênero. Os princípios, juntamente com sua extensão de 2017, possuem um conjunto de orientações de especialistas para aplicação das regras e princípios do Direito Internacional Público nos casos de violação de Direitos Humanos de lésbicas, gays, bissexuais, transexuais, travestis, transgêneros e intersexuais. É importante salientar que o objetivo do manuscrito não era o de criar novos direitos à comunidade LGBTI, mas refletir os preceitos dos principais instrumentos internacionais sobre Direitos Humanos, demonstrando que estes direitos também se aplicam a essa comunidade, essa minoria em situação de vulnerabilidade, e que os Estados têm obrigações de protegê-los (ALAMINO; DEL VECCHIO, 2018).

Os princípios de 1 a 3 do documento tratam de aspectos gerais dos Direitos Humanos, visando garantir o tratamento não discriminatório pelos Estados. Já o 
princípio 17 expõe o direito ao padrão mais alto alcançável de saúde física e mental e o princípio 18 nos traz o direito de proteção contra abusos médicos, ressaltando que:

\begin{abstract}
Nenhuma pessoa deve ser forçada a submeter-se a qualquer forma de tratamento, procedimento ou teste, físico ou psicológico, ou ser confinada em instalações médicas com base na sua orientação sexual ou identidade de gênero. A despeito de quaisquer classificações contrárias, a orientação sexual e identidade de gênero de uma pessoa não são, em si próprias, doenças médicas a serem tratadas, curadas ou eliminadas. (YOGYAKARTA PRINCIPLES, 2007, p. 26, tradução nossa).
\end{abstract}

Em 2011, O Supremo Tribunal Federal brasileiro se tornou a primeira corte suprema a reconhecer a união civil de pessoas do mesmo sexo como entidade familiar, recebendo da UNESCO certificado de patrimônio documental da humanidade no ano de 2018 (INSTITUTO BRASILEIRO DE DIREITO DE FAMÍLIA, 2018). A decisão citou os Princípios de Yogyakarta como diretriz.

O documento, apresentado ao Conselho de Direitos Humanos da ONU em 2007, inspirou a proposta da Declaração das Nações Unidas sobre orientação sexual e identidade de gênero de 2008. Essa declaração, feita por iniciativa da França e com apoio de diversos países da Europa e América Latina, condenou as violações de Direitos Humanos pela homofobia e transfobia ao redor do mundo (UNITED NATIONS GENERAL ASSEMBLY, 2008, tradução nossa). Destinada a ser uma resolução, resultou na realização de outra declaração, em sentido contrário, capitaneada pela Liga Árabe. O novo documento contou com o apoio de 60 países. Segundo a Organização da Conferência Islâmica: "[...] o esforço ameaça minar o quadro internacional de direitos humanos ao tentar normalizar a pedofilia, entre outros atos [...]" (MACFARQUHAR, 2008, tradução nossa).

A fala da oposição, que associa a homossexualidade à pedofilia, demonstra bem a discriminação enraizada nas sociedades ao redor do globo. Tal tipo de pensamento, além de legitimar violências, inviabiliza o acesso efetivo do grupo LGBTI à Direitos Humanos essenciais. Vale frisar que a declaração contrária não foi assinada exclusivamente por países do Oriente, ou de cultura islâmica.

Apenas em 2011, foi divulgado pelo Escritório do Alto Comissário das Nações Unidas para os Direitos Humanos (EACDH) o primeiro relatório sobre direitos do grupo LGBTI. Nele, foi detalhado como essa comunidade é morta ou violentada por 
conta de sua orientação sexual e identidade de gênero. Além disso, apontou a negligência dos governos na criminalização da homofobia e transfobia, uma vez que:

Se a lei reflete essencialmente o sentimento homofóbico, então ela legitima a homofobia na sociedade em geral. Se o Estado trata as pessoas como de segunda classe ou, pior, como criminosos, então está convidando as pessoas a fazerem a mesma coisa (UNITED NATIONS, 2011, tradução nossa).

Uma contribuição importante foi a sugestão de campanhas de informação públicas de combate à homofobia, principalmente nas escolas; e de capacitação da polícia e aplicadores da lei para garantir o tratamento justo à população LGBTI (UNITED NATIONS, 2012, tradução nossa).

Com base no quadro exposto, observa-se um grande esforço da ordem internacional na positivação e efetivação do acesso à saúde pelo grupo LGBTI. No entanto, a discriminação ainda faz parte das sociedades no geral. Isso tem influência da omissão legislativa, ao mesmo tempo em que a influencia, pois, como já mencionado, a sociedade inspira os valores a serem tutelados pelo Direito.

Um dos maiores exemplos de comportamento discriminatório se deu através da Organização Mundial da Saúde. Até 2019, a OMS considerava a transexualidade como doença mental. Apenas em 25 de maio do referido ano, fora aprovada uma resolução para remover o "transtorno de identidade de gênero" da classificação oficial de doenças e criado um novo capítulo no documento, dedicado à saúde sexual (NAÇÕES UNIDAS BRASIL, 2019). Com isso, buscou-se reduzir o estigma e garantir o acesso a intervenções como cirurgias de redesignação sexual.

Outro exemplo é a chamada terapia de reorientação sexual, cujos métodos procuram eliminar a homossexualidade. Tal prática foi recorrente no Brasil por muito tempo e ainda hoje deixa resquícios, como comprova liminar concedida pelo STF cassando a decisão de um juiz federal que permitia a realização do tratamento (FARIAS, 2019). A ideia de impor uma mudança de orientação sexual já é absurda considerando que todos são iguais perante a lei. Além disso, tal fato explana que o próprio sistema judiciário é conivente com violações de direitos, sendo necessária a interferência da instância judicial máxima do Estado para barrar a ação.

\section{ENFRENTAMENTO DURANTE A PANDEMIA DA COVID-19}


A pandemia da Covid-19 impactou de forma gigantesca as sociedades, desde o aspecto sanitário ao econômico. Em meio a tantas dificuldades, é importante atentar às populações historicamente oprimidas, pois estas já enfrentam problemas diariamente e, com a pandemia, são ainda mais marginalizadas.

No caso do grupo LGBTI, o longo histórico de discriminação faz com que seja ainda mais difícil ter acesso aos Direitos Humanos, e, consequentemente, a efetivação do direito à saúde. Observa-se, nesse período, graves prejuízos à saúde mental e ao acesso aos locais de atendimento, para tratar de demandas específicas.

É importante salientar que a promoção de direitos está intimamente ligada à ideologia do governo vigente. No cenário brasileiro, tem-se, a partir da eleição de Jair Bolsonaro, em 2018, um afastamento da cooperação internacional na área dos Direitos Humanos. No cenário atual:

\footnotetext{
Destaca-se o retrocesso no protagonismo brasileiro na pauta de gênero e direitos LGBTI+ a partir dos posicionamentos recorrentes do Ministério das Relações Exteriores que integra o Poder Executivo, o que levou inclusive a questionamentos dos movimentos sociais junto ao STF (OLIVEIRA; CARVALHO; JESUS, 2020, p. 74-75).
}

No ano de 2019, o ministro das relações exteriores, Ernesto Araújo, declarou que a política externa brasileira é contrária ao uso da palavra 'gênero'. Além disso, 0 Brasil votou, por exemplo, a favor de uma proposta do governo do Egito para suprimir o termo 'direito à saúde sexual e reprodutiva' em resolução sobre o casamento forçado de meninas (HAJE, 2019).

Sobre a questão da palavra 'gênero', o caso chegou até o Supremo Tribunal Federal, através de demanda da Associação Brasileira de Lésbicas, Gays, Bissexuais, Travestis, Transexuais e Intersexos. A Corte pediu esclarecimentos do ministro das relações exteriores sobre a restrição do termo nas negociações internacionais (ITAMARATY, 2019). Para a Associação, a ação do ministro vai em contramão ao entendimento do STF, uma vez que já foi reconhecida a possibilidade de alteração de nome e gênero pelos transgêneros no assento de registro civil mesmo sem a realização de procedimento cirúrgico de redesignação de sexo.

No início do mês de abril desse ano, foi lançada uma cartilha pelo Ministério da Mulher, da Família e dos Direitos Humanos (MMFDH) com orientações ao grupo LGBTI para prevenção do coronavírus. O documento abordava profissionais do sexo 
e usuários de droga, o que gerou diversas críticas pela população. Dessa forma, a Secretaria Nacional de Proteção Global admitiu o equívoco e divulgou uma nova versão, na qual foram feitas recomendações gerais (GOVERNO FEDERAL, 2020).

A versão final da cartilha declara que a saúde mental importa e recomenda conversas virtuais com amigos e familiares. No entanto, trata-se de uma recomendação muito rasa, e exime a responsabilidade estatal no complexo de bemestar físico e mental da população, além de não tratar de aspectos específicos que afligem o grupo LGBTI.

De acordo com cientistas sociais da Universidade de Sussex e do Colégio Universitário de Londres, a pandemia do coronavírus causa um efeito desproporcional à população LGBTI. Através da pesquisa chamada 'Queerantine', descobriu-se que a maioria desse grupo enfrentou problemas com a saúde mental durante o isolamento, tanto por se sentirem solitários - reforçando o sentimento de exclusão anterior à pandemia - quanto pela necessidade, muitas vezes, de retornarem à casa de familiares que não compreendem as questões de orientação sexual e identidade de gênero.

Corrobora para esse cenário a diminuição da capacidade de atendimento do sistema de saúde, para tratar os enfermos da Covid-19 e faz com que necessidades específicas não sejam atendidas. Para os pesquisadores:

\footnotetext{
Isso é especialmente verdadeiro para pessoas trans cujo acesso à clínicas de identidade de gênero, hormônios e cirurgias foi significativamente restringido, causando uma extensão inevitável do tempo de espera por cuidados de saúde relacionados à transição que, antes da pandemia já se estendia para entre dois e quatro anos (VOWLES, 2020, tradução nossa).
}

No Brasil, um levantamento feito pelo coletivo \#VoteLGBT demonstrou que os principais impactos da pandemia na população LGBTI foram: piora na saúde mental; afastamento da rede de apoio; e falta de fonte de renda (proveniente do desemprego compulsório) (DIAGNÓSTICO, 2020). Sobre a saúde mental, é preciso entender que doenças como ansiedade e depressão já são mais recorrentes entre esse grupo, como resultado do preconceito enfrentado frequentemente. Com o isolamento social, elas são intensificadas, principalmente porque muitas dessas pessoas sofrem violência psicológica e física no ambiente familiar. 
Acerca da violência doméstica, o Escritório do Alto Comissário para Direitos Humanos da ONU pontuou que jovens e idosos LGBT são forçados a ficarem em casa com familiares intolerantes, o que agrava os abusos físicos e emocionais (UNITED NATIONS, 2020a, tradução nossa). Nas ruas, a violência também é notada, principalmente contra os transexuais e travestis. No primeiro semestre de 2020, o aumento no número de assassinatos foi na ordem de $49 \%$ contra a população transexual (ASSOCIAÇÃO NACIONAL DE TRAVESTIS E TRANSEXUAIS, 2020).

Além disso, muitos desse grupo não possuem cadastro nas organizações governamentais para algum tipo de benefício, e ainda têm dificuldade de fazer documentação e acessar as políticas públicas de assistência. Na área da saúde, tratamentos para feminização dos corpos trans e travestis podem comprometer a saúde em caso de desassistência, o que pode ocasionar fator de risco para contrair coronavírus devido a processos infecciosos, por exemplo (ONU MULHERES BRASIL, 2020).

Diante das situações apresentadas, e com enfoque nos prejuízos à saúde mental, destaca-se a omissão da atividade estatal na proteção dos indivíduos LGBTI. Não é observada uma mobilização de esforços para auxílio psicológico, tampouco uma postura de criminalização por parte do poder Legislativo, cabendo, no geral, à ações do Poder Judiciário. Pelo contrário, conforme demonstrado, os ministros do atual governo deslegitimam as causas do grupo.

Como exemplo de ação estatal benéfica pode-se apontar a iniciativa do governo do Mato Grosso do Sul de promover uma roda de conversa online com especialistas sobre saúde mental e população LGBT+. Em convergência com o 'Setembro Amarelo', mês de prevenção ao suicídio, o evento buscou discutir não apenas os problemas já mencionados, como também situações de constrangimento nos centros de atendimento (TENTE, 2020).

Por vezes, os próprios profissionais de saúde podem promover tratamento discriminatório, o que faz com que muitas pessoas do grupo LGBTI não se sintam confortáveis para procurar ajuda. Segundo a psicóloga Beatriz Machado: "[...] é comum ouvir de pacientes LGBTs violências sofridas dentro dos consultórios, que relatam não terem tido suas queixas e dores legitimadas no espaço terapêutico [...]" (VASCONCELOS, 2020). 
Sendo assim, apesar da atitude louvável do governo do Mato Grosso do Sul, trata-se de uma ação pontual. Ainda é necessário pensar em formas de ampliar o atendimento psicológico pelo SUS, além de promover uma espécie de capacitação dos profissionais de saúde, para que estejam aptos a lidar com as demandas do grupo LGBTI durante a pandemia (e fora dela). Ademais, é mister entender a necessidade de que o governo não tenha atitudes discriminatórias, protegendo os direitos das minorias, conforme as diretrizes do Direito Internacional Público.

\section{A TEORIA DA EFICÁCIA HORIZONTAL DOS DIREITOS HUMANOS: UMA POSSÍVEL SOLUÇÃO}

Ao observar a insuficiência do papel do Estado na salvaguarda dos Direitos Humanos, em específico na matéria desse estudo, é preciso pensar em alternativas. O Estado, ao mesmo tempo em que protege direitos, também os viola, sendo necessária a participação ativa da sociedade civil na sua reinvindicação e proteção. Conforme mencionado anteriormente, os direitos sociais não devem ser preocupação exclusiva do Estado, mas de toda a sociedade, a qual deve atuar: pressionando os governos a tutelarem os valores dispersos; e aplicando os princípios de Direitos Humanos nas suas relações privadas.

Para tal propósito, destaca-se a teoria da eficácia horizontal dos Direitos Humanos, segundo a qual as pessoas não podem, em suas relações privadas, agirem de maneira nociva à dignidade humana (BARRETTO, 2017). No âmbito dos direitos sociais, observa-se que, apesar de serem dever do Estado, os particulares se mobilizam em busca de garantir o 'mínimo existencial' aos grupos vulneráveis. Para Otero e Rodrigues (2014, p. 108-109): "[...] através de associações, organizações, instituições, grupos com movimentos sociais, alicerçados com o espírito da fraternidade e solidariedade, busca-se alcançar o bem-estar do próximo".

Utilizamo-nos, portanto, da perspectiva do Direito fraterno para entender a vinculação da sociedade civil. Segundo essa corrente, o direito atual deve ser analisado como um direito entre 'irmãos', no sentido da palavra latina frater. Logo, "[...] não parte da decisão de um soberano, [...] mas de um acordo estabelecido entre partes iguais. É um pacto acordado a partir de regras mínimas de convivência [...]" (VIAL, 2008, p. 68). 
A ideia de fraternidade foi amplamente divulgada durante a Revolução Francesa, no século XVIII, na busca da equiparação das condições do povo. Destacase, nesse período, a filosofia contratualista de Jean-Jacques Rousseau. Para o estudioso, a desigualdade nasce com o início da sociedade civil. Antes das organizações sociopolíticas, no estado natural, o homem era detentor da 'comiseração', ato de bondade ou empatia. O francês prega, então, a reformulação de concepções como a comiseração com base na racionalidade moderna, a fim de se garantir a igualdade da população.

A fraternidade foi consagrada também pela Declaração Universal de Direitos Humanos, promulgada pela ONU em 1948. Seu artigo $1^{\circ}$ dispõe que: "Todos os seres humanos nascem livres e iguais em dignidade e em direitos. Dotados de razão e de consciência, devem agir uns para com os outros em espírito de fraternidade." (UNITED NATIONS, 1948, tradução nossa, grifo nosso). Além disso, a terceira dimensão dos Direitos Humanos se concentra no ideal da fraternidade, buscando o progresso, o desenvolvimento e a qualidade de vida. Nessa ótica, os direitos possuem titularidade coletiva e aplicação universal.

A possibilidade do Direito Fraterno servir como análise do acesso à saúde nos dias atuais se dá pelo fato de que não é suficiente garantir o direito à saúde na carta constitucional, é preciso viabilizar sua promoção em demandas concretas. Não obstante, as doenças não respeitam os limites territoriais, por isso, não basta a adoção de medidas regionais pelos governos, pois inerente ao Direito fraterno a ideia de universalidade (VIAL, 2008).

De volta à teoria da eficácia horizontal dos Direitos Humanos, surge uma dúvida: os indivíduos não seriam titulares dos direitos prestacionais, que seriam dever do Estado? Para a corrente doutrinária que defende a eficácia horizontal indireta sim. Segundo esses autores, o legislador seria o destinatário das normas, ao passo que: "[...] os direitos fundamentais consubstanciam defesa à atuação estatal, e, como ordem objetiva de valores, não podem ser enquadrados como direitos subjetivos constitucionais, afastando eficácia nas relações privadas [...]" (FARIA, 2012, p. 41). Nesse caso, para possibilitar a atuação dos particulares, seria necessária mediação legislativa infraconstitucional. 
Por outro lado, os autores que defendem a eficácia horizontal direta, ou eficácia imediata, formulam que os indivíduos são também destinatários das normas de Direitos Humanos. Logo, não há necessidade de intervenção legislativa. Na esfera do Direito interno, "[...] os direitos fundamentais são a expressão máxima dos valores adotados por um Estado de Direito, devendo ser opostos a todos os cidadãos [...]" (OTERO; RODRIGUES, 2014, p. 117). No Brasil, observam-se entendimentos do Supremo Tribunal Federal, em convergência com essa corrente.

A partir do momento em que o Estado não atende à todas as demandas, a sociedade deve, de forma razoável, auxiliar na efetivação dos Direitos Humanos. Isso não significa que as pessoas tenham a obrigação de arcar com despesas ou de dedicar suas vidas à inclusão de todos os seres, mas, a premissa principal é a de: agir conforme as regras e princípios dos Direitos Humanos, respeitando a dignidade humana e sendo avesso à violência e à discriminação. Secundariamente, auxiliando, quando possível, os grupos minoritários a terem seus direitos efetivados e pressionando os Estados para sua realização.

No contexto da pandemia do coronavírus, tem-se organizações da sociedade civil trabalhando freneticamente para suprir as lacunas deixadas pelos Estados. Particulares trabalharam na coleta e distribuição de alimentos; confecção e distribuição de máscaras e produtos de higiene; e criação de redes de comunicação em busca de preservação da saúde mental. Dessa forma:

Este sistema complexo de alerta precoce, senso de comunidade, defesa e acompanhamento que foi forjado pela dedicação dos defensores dos Direitos Humanos das pessoas LGBT em todo o mundo demonstrou sua capacidade única de responder com eficiência às necessidades nos níveis mais íntimos e locais. [...] Também é fundamental para condenar e erradicar o flagelo da criminalização e uma transformação social de amplitude sem precedentes (UNITED NATIONS, 2020b, tradução nossa).

No Brasil, destaca-se como exemplo de iniciativas da sociedade civil durante a pandemia: campanha do coletivo \#VoteLGBT de arrecadação de fundos para entidades que prestam amparo à comunidade LGBTI; campanhas de venda de máscaras e doações para distribuição de cestas básicas pelo Centro LGBTS+ de Brasília; iniciativa da Universidade Estadual de São Paulo de criar uma rede de apoio para tratar das questões psicológicas durante o isolamento (TARASIUK, 2020), entre outras. 


\section{CONSIDERAÇÕES FINAIS}

Considerando ser vital o direito à saúde, é preciso garantir os meios de sua realização. Como demonstrado, a saúde não é apenas a ausência de comorbidade física, mas sim um complexo de bem-estar físico e mental. Ao analisar esse fato, percebe-se que grupos minoritários ainda não conseguem acessá-lo efetivamente, em especial a população LGBTI.

No contexto da pandemia do coronavírus, observa-se uma marginalização maior do grupo, principalmente com relação à saúde mental. No entanto, não se nota uma mobilização do Estado para a proteção do grupo, ao mesmo tempo em que - Poder Legislativo se mostra inerte na criminalização de atos homofóbicos e transfóbicos, relegando a tarefa ao Poder Judiciário quando provocado.

A fim de suprir as lacunas deixadas pelo Estado, tem-se como alternativa o auxílio da sociedade civil, com base na teoria da eficácia Horizontal dos Direitos Humanos. Os documentos internacionais de Direitos Humanos e a Constituição Federal brasileira possuem força normativa. Essa força, atrelada à noção de dignidade da pessoa humana e ao princípio da solidariedade, fundamentam o porquê os direitos sociais vinculam também os particulares (MATEUS, 2007).

É importante destacar que o presente estudo não busca isentar a responsabilidade do Estado, mas sim pensar em uma atuação paralela em busca da efetivação do acesso à direitos fundamentais. As ações da sociedade civil devem não apenas auxiliar nas demandas, mas também pressionar a tutela estatal. Resgatando as ideias de Monstesquieu, no Espírito das Leis:

Não basta dar esmolas para um homem nu que encontramos na rua, pois esse ato não exime o estado de suas obrigações com as políticas sociais, uma vez que é sua função assegurar a todos os cidadãos as condições mínimas de sobrevivência (VIAL, 2008, p. 81).

\section{REFERÊNCIAS}

AITH, Fernando. Curso de direito sanitário: a proteção do direito à saúde no Brasil. São Paulo: Quartier Latin, 2007. 
ALAMINO, Felipe Nicolau Pimentel; DEL VECCHIO, Victor Antonio. Os Princípios de Yogyakarta e a proteção de direitos fundamentais das minorias de orientação sexual e de identidade de gênero. Revista da Faculdade de Direito da Universidade de São Paulo, São Paulo, v. 113, p. 645-668, jan./dez. 2018. Disponível em: http://www.revistas.usp.br/rfdusp/article/view/156674/152166. Acesso em: 04 set. 2020.

ASSOCIAÇÃO NACIONAL DE TRAVESTIS E TRANSEXUAIS. Boletim no 02/2020: Assassinatos contra travestis e transexuais em 2020. Rio de Janeiro: Associação Nacional de Travestis e Transexuais, 04 de maio 2020. Disponível em: https://antrabrasil.files.wordpress.com/2020/05/boletim-2-2020-assassinatosantra.pdf. Acesso em: 12 ago. 2020.

BARRETTO, Rafael. Direitos Humanos. 7. ed. Salvador: Editora Juspodivm, 2017.

BRASIL. [Constituição (1988)]. Constituição da República Federativa do Brasil de 1988. Brasília, DF: Presidência da República, 1988. Disponível em: http://www.planalto.gov.br/ccivil_03/constituicao/constituicao.htm. Acesso em: 31 ago. 2020.

BRASIL. Decreto n. ${ }^{\circ}$ 591, de 6 de julho de 1992. Dispõe sobre o Pacto Internacional de Direitos Econômicos, Sociais e Culturais. Brasília, DF: Presidência da República, 1992. Disponível em: http://www.planalto.gov.br/ccivil_03/decreto/19901994/d0591.htm. Acesso em: 6 ago. 2020.

D 'ÁVILA, Luciana Souza; SALIBA, Graciane Rafisa. A efetivação do direito à saúde e sua interface com a justiça social. Revista de Direito Sanitário, São Paulo, v. 17, n. 3, p. 15-38, nov. 2016/ fev. 2017. Disponível em: http://www.periodicos.usp.br/rdisan/article/view/127772/124770. Acesso em: 02 set. 2020.

DIAGNÓSTICO LGBT+ na Pandemia: desafios da comunidade LGBT+ no contexto de isolamento social em enfrentamento à pandemia de coronavírus. Vote LGBT, [S. I.], junho de 2020. Disponível em: https://www.votelgbt.org/pesquisas. Acesso em: 21 set. 2020.

FACHIN, Zulmar. Curso de Direito Constitucional. 8. ed. rev. e atual. São Paulo: Editora Verbatim, 2019.

FARIA, Rodrigo Martins. A eficácia horizontal dos direitos fundamentais no plano processual das relações privadas e a jurisprudência do Supremo Tribunal Federal após a Consituição Federal de 1988. Revista Jurisprudência Mineira, Belo Horizonte, ano 63, n. 203, p. 23-47, out./dez. 2012. Disponível em: https://bd.tjmg.jus.br/jspui/bitstream/tjmg/382/1/D3v2032012.pdf. Acesso em: 24 set. 2020. 
FARIAS, Victor. Ministra do STF suspende decisão que permitia terapia da 'cura gay'. O Globo, [S. I.], 24 de abril de 2019. Disponível em:

https://oglobo.globo.com/sociedade/ministra-do-stf-suspende-decisao-que-permitiaterapia-da-cura-gay-23618721. Acesso em: 05 set. 2020.

GOVERNO FEDERAL. Ministério lança material voltado ao grupo LGBT para prevenção do coronavírus. Governo Federal, [S. I.], 2 de abril de 2020. Disponível em: https://www.gov.br/mdh/pt-br/assuntos/noticias/2020-2/abril/ministerio-lancamaterial-voltado-ao-publico-lgbt-para-prevencao-do-coronavirus. Acesso em: 21 set. 2020.

HAJE, Lara. Ministro confirma diretriz da política externa contra conceito de gênero e contra aborto. Câmara dos Deputados, [S. I.], 7 de agosto de 2019. Disponível em: https://www.camara.leg.br/noticias/567468-ministro-confirma-diretriz-dapolitica-externa-contra-conceito-de-genero-e-contra-aborto/. Acesso em: 21 set. 2020.

INSTITUTO BRASILEIRO DE DIREITO DE FAMÍLIA. Decisão do STF sobre união homoafetiva é reconhecida como patrimônio da humanidade da UNESCO. Instituto Brasileiro de Direito de Família, [S. I.], 12 de dezembro de 2018. Disponível em: https://www.ibdfam.org.br/noticias/namidia/17139/Decis\%C3\%A30+do+STF+sobre+uni\%C3\%A3o+homoafetiva+\%C3\% A9+reconhecida+como+patrim\%C3\%B4nio+documental+da+humanidade+da+UNE SCO. Acesso em: 05 set. 2020.

ITAMARATY deve explicar ao Supremo orientação sobre gênero. Consultor Jurídico, [S. I.], 8 de outubro de 2019. Disponível em: https://www.conjur.com.br/2019-out-08/itamaraty-explicar-supremo-orientacaogenero. Acesso em: 21 set. 2020.

MACFARQUHAR, Neil. In a First, Gay Rights are pressed at the U.N. The New York Times, [S. I.], 18 de dezembro de 2008. Disponível em: https://www.nytimes.com/2008/12/19/world/19nations.html. Acesso em: 04 set. 2020.

MARTINS, José Renato; MALUF, Iaci Moura Kehl. Contaminação dolosa da SIDA por meio de relações sexuais e direito penal: legitimidade da tutela jurídica e limite de intervenção em face dos princípios constitucionais e da dignidade da pessoa humana. In: SIMPÓSIO NACIONAL DE DIREITO CONSTITUCIONAL, 11., 2016. Anais [...]. Curitiba: Academia Brasileira de Direito Contitucional, 2016. p. 490-523. Disponível em http://abdconst.com.br/anais4/Jose\%20Renato\%20Martins.pdf. Acesso em: 23 ago. 2020.

MATEUS, Cibele Gralha. Direitos Fundamentais Sociais e Relações Privadas: o caso do direito à saúde na Constituição brasileira de 1988. 2007. Dissertação (Mestrado em Direito) - Faculdade de Direito, Pontifícia Universidade Católica do Rio Grande do Sul, Porto Alegre, 2007. Disponível em: 
http://repositorio.pucrs.br/dspace/bitstream/10923/2309/1/000395857-

Texto\%2BParcial-0.pdf . Acesso em: 24 set. 2020.

MAZZUOLI, Valerio de Oliveira. Curso de Direitos Humanos. 6. ed. rev. atual. e ampl. São Paulo: Editora Método, 2019.

MAZZUOLI, Valerio de Oliveira. O Controle Jurisdicional da Convencionalidade das Leis. 2. ed. São Paulo: Revista dos Tribunais, 2011.

NAÇÕES UNIDAS BRASIL. Discriminação impede que pessoas LGBT tenham acesso à saúde. Nações Unidas Brasil, [S. I.], 14 de dezembro de 2016. Disponível em: https://brasil.un.org/pt-br/75217-discriminacao-impede-que-pessoas-lgbt-tenhamacesso-saude-alerta-opas. Acesso em: 6 ago. 2020.

NAÇÕES UNIDAS BRASIL. OMS retira a transexualidade da lista de doenças mentais. Nações Unidas Brasil, [S. I.], 6 de junho de 2019. Disponível em: https://brasil.un.org/pt-br/83343-oms-retira-transexualidade-da-lista-de-doencasmentais. Acesso em: 05 set. 2020.

NOGUEIRA, Marco Aurélio. Os Direitos Sociais como causas cívicas. Saúde e Sociedade, [S. I.], v. 11, n. 1, p. 15-24, 2002. Disponível em: https://www.scielo.br/pdf/sausoc/v11n1/04.pdf. Acesso em: 05 set. 2020.

OLIVEIRA, Fábio Alves Gomes; CARVALHO, Henrique Rabello de; JESUS, Jaqueline Gomes de. LGBTI+ em tempos de Pandemia da Covid-19. Diversitates

International Journal, [S. I.], v. 12, n. 2, p. 60-94, jun./dez. 2020. Disponível em: http://www.diversitates.uff.br/index.php/1diversitates-uff1/article/view/313. Acesso em: 21 set. 2020.

OLIVEIRA, Joana. Em decisão histórica, STF derruba restrição de doação de sangue por homossexuais. El País, São Paulo, 8 de maio de 2020. Disponível em: https://brasil.elpais.com/brasil/2020-05-08/em-decisao-historica-stf-derrubarestricao-de-doacao-de-sangue-por-homossexuais.html. Acesso em: 12 ago. 2020.

ONU MULHERES BRASIL. Mulheres lésbicas, bissexuais e transexuais contam os desafios da população LGBT na pandemia da Covid-19. ONU Mulheres Brasil, [S. l.], 19 de maio de 2020. Disponível em:

http://www.onumulheres.org.br/noticias/mulheres-lesbicas-bissexuais-e-transexuaiscontam-os-desafios-da-populacao-lbt-na-pandemia-da-covid-19/. Acesso em: 23 set. 2020.

ORGANIZAÇÃO PAN-AMERICANA DA SAÚDE BRASIL. Estigma e Discriminação são as principais barreiras à saúde para a população LGBT. Organização Pan-Americana da Saúde Brasil, [S. /.], 13 de dezembro de 2016. Disponível em: https://www.paho.org/bra/index.php?option=com_content\&view=article\&id=5318:es tigma-e-discriminacao-sao-as-principais-barreiras-a-saude-para-a-populacaolgbt\&Itemid=820. Acesso em: 04 set. 2020. 
OTERO, Cleber Sanfelici; RODRIGUES, Mithieli Tatiane. Eficácia Horizontal dos direitos fundamentais sociais e solidários nas relações privadas. In: IOCOHAMA, Celso Hiroshi. $\mathbf{O}$ acesso à justiça e os direitos fundamentais em debate. Umuarama: Universidade Paranaense, 2014. v. 1, p. 108-134. Disponível em: https://presencial.unipar.br/files/publicao_academica/acesso_justica_e_direitos_fund amentais_em_debate_I_versao_final_1.pdf\#page=108. Acesso em: 12 ago. 2020.

RDC TV. População LGBT: os diversos reflexos do preconceito acentuados pela pandemia. [S. I.], 15 de julho de 2020. Disponível em: https://rdctv.com.br/destaques-do-dia/populacao-lgbt-os-diversos-reflexos-dopreconceito-acentuados-pela-pandemia/. Acesso em: 6 ago. 2020.

SARLET, Ingo Wolfgang. A Eficácia dos Direitos Fundamentais. 11. ed. rev. e atual. Porto Alegre: Livraria do Advogado Editora, 2012.

TARASIUK, Karina. Comunidade universitária ajuda LGBTs a enfrentar desafios durante a pandemia. Jornal da USP, [São Paulo], 1 de junho de 2020. Disponível em: https://jornal.usp.br/universidade/comunidade-universitaria-ajuda-lgbts-aenfrentarem-desafios-durante-a-pandemia/. Acesso em: 24 set. 2020.

TENTE, Jaqueline Hahn. Roda de conversa debaterá Saúde Mental e População LGBT. Portal do Governo de Mato Grosso do Sul, [S. I.], 16 de setembro de 2020. Disponível em: http://www.ms.gov.br/roda-de-conversa-debatera-saudemental-e-populacao-lgbt/. Acesso em: 23 set. 2020.

\section{UNITED NATIONS GENERAL ASSEMBLY. Statement on Human Rights, Sexual} Orientation and Gender Identity. New York: UN General Assembly, 18 de dezembro de 2008. Disponível em: https://www.refworld.org/docid/49997ae312.html. Acesso em: 04 set. 2020.

UNITED NATIONS. Office of the high commissioner for human rights. Born free and equal: sexual orientation and gender identity in international human rights law. United Nations: Nova York, 2012. Disponível em: https://www.ohchr.org/Documents/Publications/BornFreeAndEqualLowRes.pdf. Acesso em: 05 set. 2020.

UNITED NATIONS. Office of the High Commissioner for Human Rights. Covid-19 and the Human Rights of LGBTI People: topics in focus covid-19 and the human rights of Igbti people. [S. l.: s. n.], 17 de abril de 2020a. Disponível em: https://www.ohchr.org/Documents/Issues/LGBT/LGBTIpeople.pdf. Acesso em: 23 set. 2020.

UNITED NATIONS. Office of the high commissioner for human rights. Covid 19: the suffering and resilience of LGBT persons must be visible and inform the actions of states: statement by human rights experts on the international day against homophobia, transphobia and biphobia. United Nations, [S. I.], 17 de maio de 2020b. Disponível em: 
https://www.ohchr.org/EN/NewsEvents/Pages/DisplayNews.aspx?NewsID=25884\&La ngID=E. Acesso em: 24 set. 2020.

UNITED NATIONS. UN issues first report on human rights of gay and lesbian people. UN NEWS, [S. I.], 15 de dezembro de 2011. Disponível em:

https://news.un.org/en/story/2011/12/398432-un-issues-first-report-human-rightsgay-and-lesbian-people. Acesso em: 05 set. 2020.

UNITED NATIONS. Universal Declaration of Human Rights. United Nations: [s. n.], 1948. Disponível em:

https://www.un.org/en/udhrbook/pdf/udhr_booklet_en_web.pdf. Acesso em: 24 set. 2020.

VASCONCELOS, Caê. Cuidar da saúde mental de negros e LGBTs exige combater racismo e LGBTfobia. Ponte Jornalismo, [S. I.], 17 de agosto de 2020. Disponível em: https://ponte.org/cuidar-da-saude-mental-de-negros-e-lgbts-exige-combaterracismo-e-lgbtfobia/. Acesso em: 23 set. 2020.

VIAL, Sandra Regina Martini. Saúde: um direito fundado na fraternidade. Saúde e Direitos Humanos, Brasília, ano 5, n. 5, p. 65-85, 2008. Disponível em: http://www.ensp.fiocruz.br/portal-ensp/publicacoes/saude-e-direitoshumanos/pdf/sdh_2008.pdf\#page=65. Acesso em: 24 set. 2020.

VOWLES, Neil. New Queerantine survey to highlight impact of Coronavirus on LGBTQ+ community. University of Sussex, [S. l.], 19 de maio de 2020. Disponível em: http://www.sussex.ac.uk/broadcast/read/52043. Acesso em: 21 set. 2020.

WORLD HEALTH ORGANIZATION. Basic documents: forty-ninth edition: including amendments adopted up to 31 May 2019. Genevra: World Health Organization, 2020. Disponível em: https://apps.who.int/gb/bd/pdf_files/BD_49th-en.pdf\#page=7. Acesso em: 02 set. 2020.

YOGYAKARTA PRINCIPLES. The Yogyakarta Principles: principles on the application of international human rights law in relation to sexual orientation and gender identity. Março de 2007. Disponível em: http://yogyakartaprinciples.org/wpcontent/uploads/2016/08/principles_en.pdf. Acesso em: 04 set. 2020. 